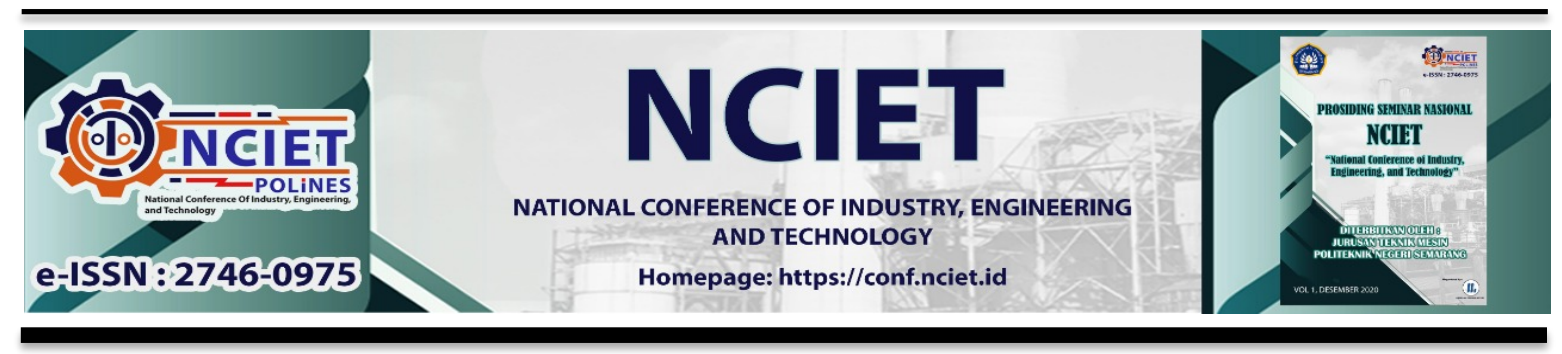

Prosiding Seminar Nasional NCIET Vol.1 (2020) B461-B474

$1^{\text {st }}$ National Conference of Industry, Engineering and Technology 2020,

Semarang, Indonesia.

\title{
PERANCANGAN ELBOW CRUTCH PORTABLE BERBASIS SENSOR ULTRASONIC
}

\author{
Ahmad Nasrul Sidik*, Irfan Santosa, Ahmad Farid \\ Teknik Mesin, Fakultas Teknik UPS Tegal \\ Jl. Halmahera Km. 1. Tegal, 52121 \\ *E-mail: mesinftups@gmail.com
}

\begin{abstract}
ABSTRAK
Alat bantu jalan sangat penting bagi penderita cedera lutut/ tungkai dan penyandang disabilitas untuk membantu jalan. Kruk merupakan salah satu alat bantu jalan yang ringan dan mudah digunakan namun sulitnya dalam penyimpanan. Oleh karena itu tujuan dari penelitian ini adalah untuk merancang dan membuat prototipe kruk siku lipat portabel dan penambahan sensor ultrasonik untuk mendeteksi rintangan yang ada didepan. Dalam penelitian ini peneliti mengembangkan alat bantu jalan yang sudah ada kemudian mendesainnya menjadi lipat dan menjadi lebih praktis. Material yang digunakan adalah paduan aluminium 6063, stainless steel, dan plastik untuk box sistem kendali sensor. Dalam sistem kendali sensor terdapat beberapa komponen yaitu sensor Ultrasonic, Arduino nano, Buzzers, Baterai, LED, dan Saklar. Desain dibuat dalam bentuk 2D dan 3D untuk menentukan dimensi-dimensi yang tepat sebelum membuat prototipe kruk siku portabel. Pembuatan kruk siku portabel dibagi menjadi 3 bagian untuk dilipat lebih kecil dengan ukuran mencapai $33,5 \mathrm{~cm}$ dan tinggi kruk dapat disesuaikan $94 \mathrm{~cm}$ menjadi $112 \mathrm{~cm}$. Dalam pembuatan kotak sistem kendali sensor menggunakan printer 3D. Setelah dilakukan penelitian sistem kendali sensor yaitu pendeteksian sensor Ultrasonic dan Buzzers, 90\% hasilnya cukup presisi, bunyi kedipan objek dan pendeteksian jarak dengan membaca pada software Arduino IDE. Hasil pengujian menggunakan software simulasi solidworks, didapatkan von mises stress pada area grip tangan maksimum $8.567 \times 107 \mathrm{~N} / \mathrm{m}^{2}$ dan minimum $0.000 \times 100 \mathrm{~N} / \mathrm{m}^{2}$ dengan diketahui yield strength $2.068 \times 108 \mathrm{~N} / \mathrm{m}^{2}$, hasil perpindahan atau pergerakan maksimum karena beban pada pegangan tangan sebesar $9.083 \times 10^{-2} \mathrm{~mm}$.
\end{abstract}

Kata kunci: Kruk Siku, Portabel, Sensor Ultrasonik

\section{PENDAHULUAN}

Sakit kaki/cedera kaki maupun penyandang disabilitas bisa berdampak pada gerak dan fungsi tubuh, untuk melakukan aktifitas sehari-hari seperti berjalan dan berpindah tempat, mungkin akan memerlukan alat bantu jalan atau bantuan orang lain untuk membantu berjalan atau bergerak.

Alat bantu jalan sangat penting bagi orang sakit kaki/cedera kaki maupun penyandang disabilitas untuk membantu jalan. Meskipun dipasaran banyak sekali berbagai macam alat bantu jalan akan tetapi harus menggunakan sesuai kebutuhan. 
Kruk adalah salah satu alat bantu jalan yang cukup ringan dan mudah digunakan akan tetapi kesulitan untuk penyimpanan oleh sebab itu tujuan dari penelitian ini yaitu perancangan dan membuat prototype elbow crutch portable. Pada dasarnya penelitian ini pengembangan kruk tipe elbow yang sudah ada agar dapat dilipat untuk memudahakan dalam penyimpanan dan penambahan sensor Ultrasonic untuk pendeteksi objek halangan didepannya.

\section{Ruang lingkup penelitian}

\section{Rumusan Masalah}

1. Bagaimana perancangan dalam bentuk 2D dan 3D dan pembuatan elbow crutch portable?

2. Bagaimana proses kerja sensor ultrasonic terhadap kondisi jalan ?

3. Bagaimana flexibilitas kekuatan elbow crutch portable pada saat digunakan ?

\section{Batasan Masalah}

1. Proses pembuatan elbow crutch portable menggunakan bahan pipa Aluminium alloy 6063 dan pipa stainless steel dengan Ø 19mm - 22mm dan sensor ultrasonic berbasis arduino nano dengan berat total $0,9 \mathrm{~kg}$.

2. Tinggi maksimal elbow crutch portable $112 \mathrm{~cm}$ dan tinggi minimal $94 \mathrm{~cm}$.

3. Proses pengujian kekuatan beban tumpuan menggunakan software Solidworks.

\section{METODOLOGI PENELITIAN}

Penelitian ini kosentrasikan pada efisiensi penyimpanan alat ini dan penambahan sensor pendeteksi jalan. Mengefisiensi penyimpanan dengan cara memodifikasi elbow crutch yang panjang menjadi elbow crutch portable yang dapat dilipat dan disimpan dengan mudah. Kemudian penambahan sensor Ultrasonic untuk mendeteksi jalan dari halangan.

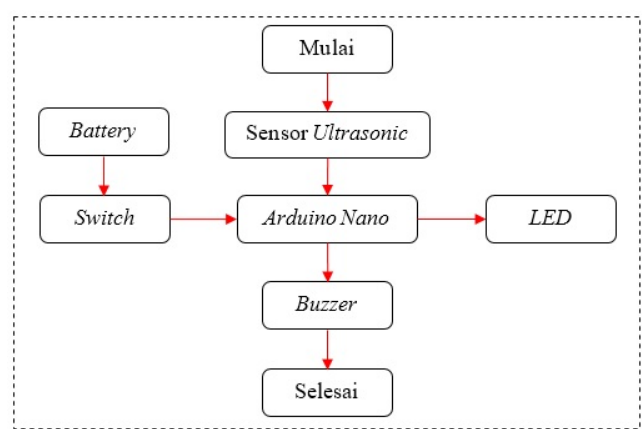

Gambar 1. Blok Diagram Sistem pada Elbow Crutch Portable 
Sensor Ultrasonic mendeteksi objek didepannya lalu hasil deteksinya dikirim ke Arduino lalu dikirim ke Buzzer bertujuan untuk sebagai tanda peringatan jika di depan sensor Ultrasonic ada halangan.

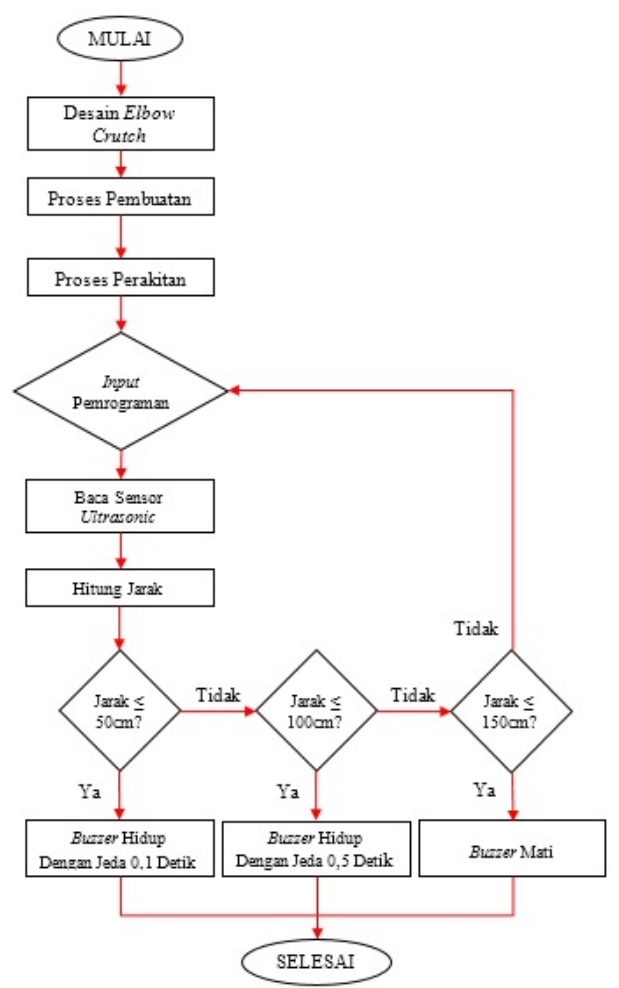

Gambar 2. Diagram Alir Elbow Crutch Portable

Menjelaskan tentang Alur Diagram Elbow crutch portable Berbasis Sensor Ultrasonic ini diawali dengan Mulai lalu perancangan dan pembuatan alat lalu input program ke Arduino nano lalu hasil program di kirim dari Arduino nano ke sensor Ultrasonic untuk membaca jarak benda yang sudah di atur dalam program. jika terdeteksi jarak di bawah 50 cm maka Buzzer on, jika tidak maka sensor akan mendeteksi jarak benda sekitar $100 \mathrm{~cm}$ jika terdeteksi maka Buzzer on, jika sensor Ultrasonic mendeteksi benda di atas $150 \mathrm{~cm}$ maka Buzzer off jika tidak maka sensor akan mendeteksi benda di depannya, Selesai.

\section{Arduino Nano Sebagai Pengendali Utama}

Arduino nano adalah salah satu papan pengembangan microcontroller yang berukuran kecil, lengkap dan mendukung penggunaan breadboard. Arduino nano diciptakan dengan basis microcontroller AT Mega 328 (untuk Arduino nano versi 3.x) atau AT Mega 168 (untuk Arduino versi 2.x). Arduino nano dihubungkan ke komputer menggunakan port USB MiniB. 


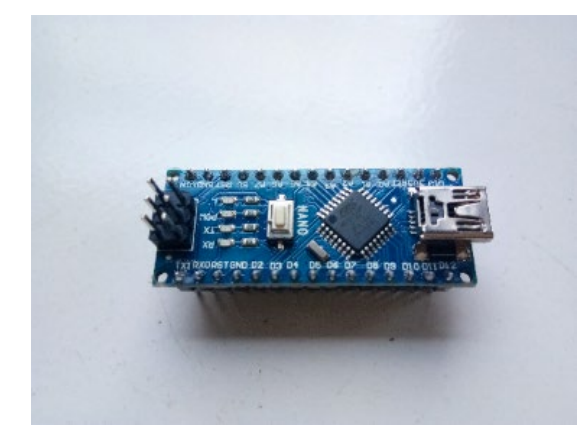

Gambar 3. Arduino nano AT Mega 328P

\section{Sensor Ultrasonic Sebagai Pendeteksi Objek}

Sensor Ultrasonic adalah sensor yang bekerja berdasarkan prinsip pantulan gelombang suara, sensor menghasilkan gelombang suara yang kemudian menangkapnya kembali dengan perbedaan waktu sebagai dasar penginderaannya. Perbedaan waktu antara gelombang suara yang dipancarkan dan yang diterima kembali adalah berbanding lurus dengan jarak atau tinggi objek yang memantulkannya. Jenis objek yang dapat diindranya adalah padat, cair, dan butiran. Tanpa kontak jarak $2 \mathrm{~cm}$ sampai 3 meter dan dapat dengan mudah dihubungkan dengan microcontroller melalui satu pin I/O saja.

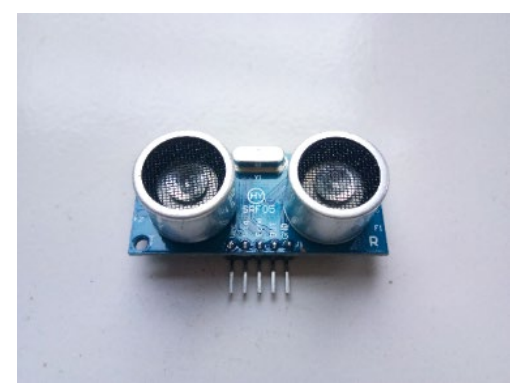

Gambar 4. Sensor Ultrasonic HY - SRF 05

\section{Buzzer Sebagai Suara Peringatan}

Buzzer adalah sebuah komponen elektronika yang berfungsi untuk mengubah getaran listrik menjadi getaran suara. Buzzer terdiri dari kumparan yang terpasang pada diafragma saat kumparan tersebut dialiri arus akan menimbulkan gaya elektro magnet dan kumparan akan tertarik ke dalam atau keluar, karena kumparan dipasang pada diafragma maka setiap gerakan kumparan akan menggerakkan diafragma secara bolak - balik sehingga membuat udara bergetar yang akan menghasilkan suara. 


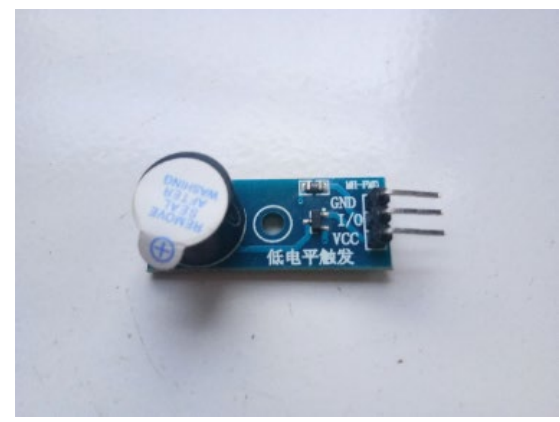

Gambar 5. Buzzer

\section{Rangkaian Sistem Kendali Sensor}

Untuk memudahkan dalam perancangan sistem kendali sensor maka diperlukan wiring diagram untuk mengetahui input dan output dari microcontroller arduino maupun dari instrumen kendali lainnya.

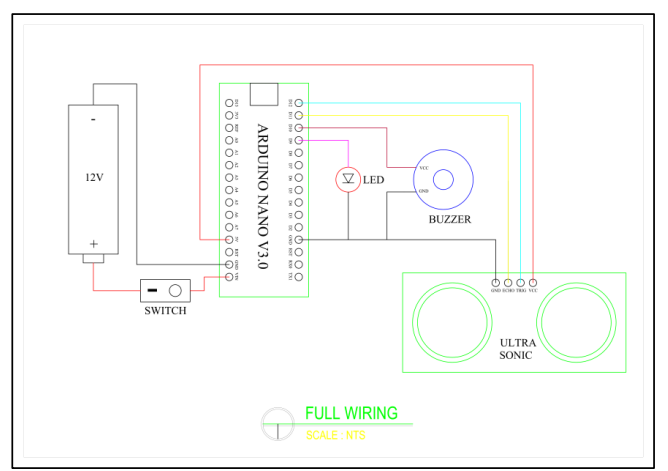

Gambar 6. Wiring diagram sistem kendali sensor

\section{HASIL DAN PEMBAHASAN}

\section{Perancangan Elbow Crutch Portable 2D dan 3D}

Desain awal alat ini dibuat dalam bentuk 2D dan 3D untuk mengetahui pembentukan alat ini di dalam software autoCAD sebelum proses produksi/ pembuatan alat.

Perbedaan alat bantu jalan elbow crutch portable dengan elbow crutch versi standart yaitu:

1. Lebih mudah dalam penyimpanan karena dapat dilipat hingga panjang $33,5 \mathrm{~cm}$ jadi dapat disimpan di tas.

2. Penambahan sensor Ultrasonic untuk mendeteksi objek didepan dengan 4 bunyi kedipan peringatan yang berbeda sesuai jarak objek. 
3. Dapat digunakan untuk segala umur dari anak-anak 10th dengan tinggi pengaturan kruk maksimal $83 \mathrm{~cm}$ dan minimal $65 \mathrm{~cm}$ hingga orang dewasa dengan tinggi maksimal $112 \mathrm{~cm}$ dan tinggi minimal $94 \mathrm{~cm}$.

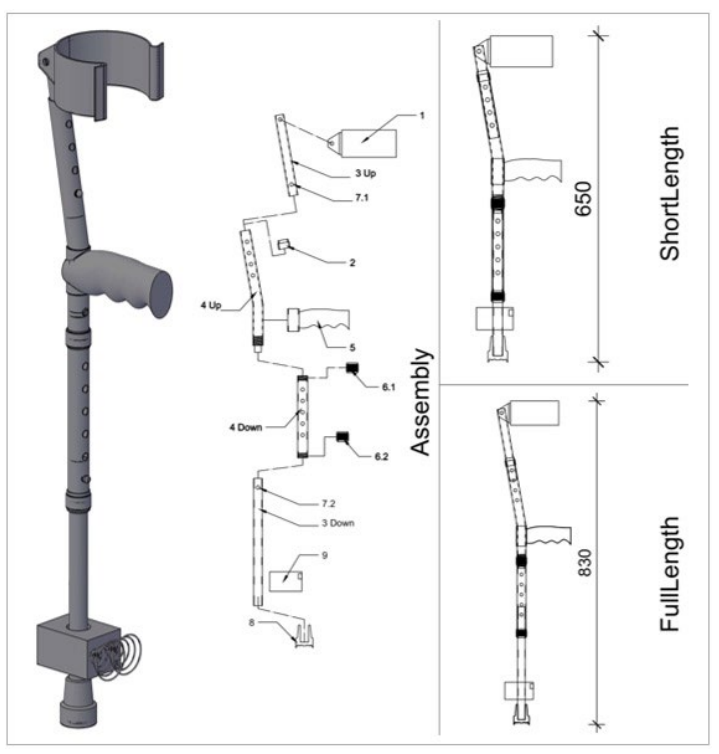

Gambar 7. Elbow Crutch Portable 2D dan 3D untuk Anak-anak

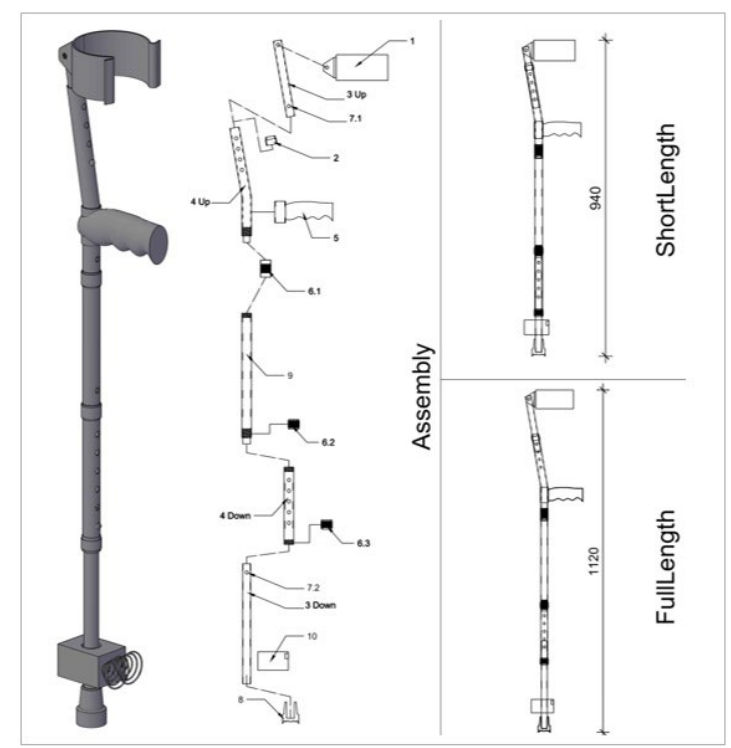

Gambar 8. Elbow Crutch Portable 2D dan 3D untuk Dewasa

\section{Pembuatan Elbow Crutch Portable dan Sistem Kendali Sensor}

1. Pembuatan ulir pada batang luar kruk dan mur pengunci

Proses dimana kruk yang masih panjang kemudian di potong dan kemudian dibuatkan ulir luar untuk memudahkan pada saat penyambungan lipatan dari batang satu dengan yang lain. 


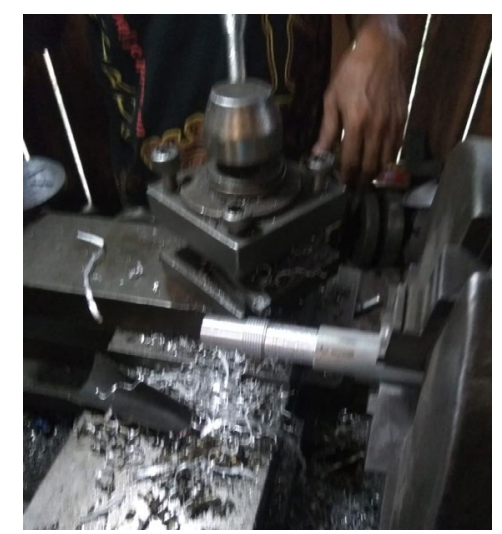

Gambar 9. Pembuatan Ulir Luar Batang Kruk

Mur pengunci ini cukup penting fungsinya karena mur ini sebagai penyambung antar batang dan juga sebagai pengunci agar batang tidak lepas dan kendor pada saat digunakan.

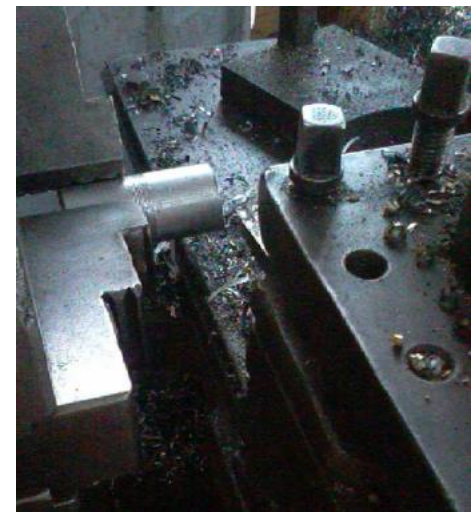

Gambar 10. Pembuatan Mur Pengunci Batang Kruk

2. Pembuatan kotak sistem kendali sensor

Bahan utama control box ini plastic PLA (Poly Latic Acid). Kotak ini berfungsi sebagai tempat komponen-komponen kendali sensor. Proses pembuatan cara cetak teknologi printer 3D dengan dimensi panjang $71 \mathrm{~mm}$, lebar $51 \mathrm{~mm}$, dan tinggi $46 \mathrm{~mm}$.

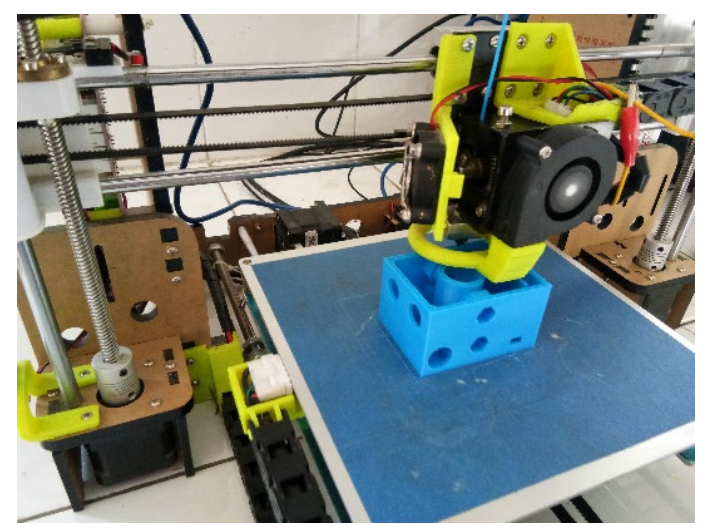

Gambar 11. Pembuatan sistem kendali sensor dengan printer 3D 
3. Pemrograman sistem kendali sensor

Sistem kendali sensor dapat digunakan jika sudah di input program sesuai kebutuhan. Pembuatan program untuk sensor Ultrasonic menggunakan software Arduino IDE.

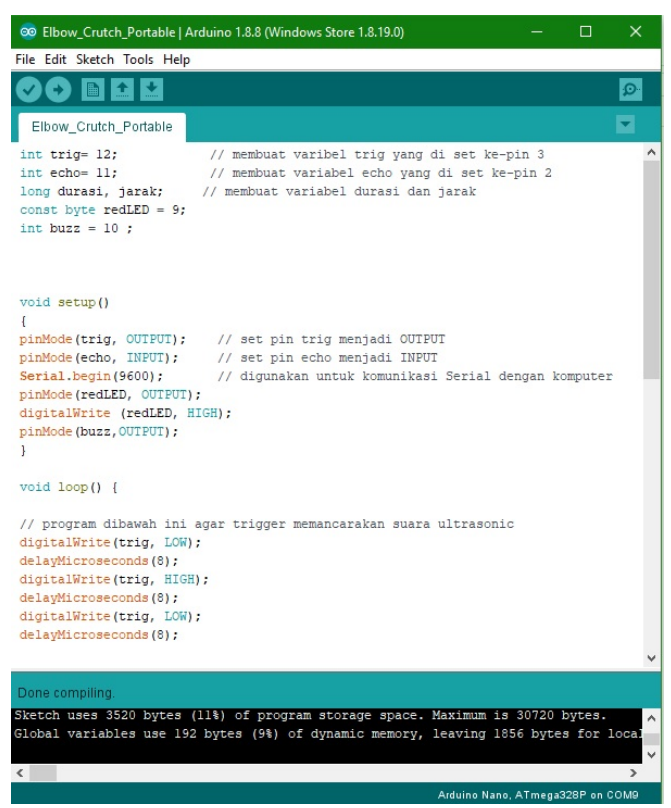

Gambar 12. Pemrograman sistem kendali sensor

\section{Pengujian Sistem Kendali Sensor}

\section{Pengujian Sensor Ultrasonic}

Ketika sensor bekerja mendeteksi jarak jangkauan objek berdasarkan program yang sudah diatur pada arduino nano. Pengujian sensor Ultrasonic dengan cara manganalisis pembacaan sensor Ultrasonic HY - SRF 05 terhadap jarak objek yang sebenarnya dan kinerja sensor apakah sensor bekerja sesuai dengan yang telah diprogramkan.

Tabel 4.1. Hasil Pengujian Sensor Ultrasonic HY - SRF 05

\begin{tabular}{|c|c|c|c|}
\hline Uji & $\begin{array}{c}\text { Jarak yang } \\
\text { ditentukan }\end{array}$ & Jarak Objek & $\begin{array}{r}\text { Jarak pada } \\
\text { Software }\end{array}$ \\
\hline \hline 1 & $5-50 \mathrm{~cm}$ & $5-50 \mathrm{~cm}$ & $5-49 \mathrm{~cm}$ \\
\hline 2 & $51-75 \mathrm{~cm}$ & $51-76 \mathrm{~cm}$ & $51-74 \mathrm{~cm}$ \\
\hline 3 & $76-100 \mathrm{~cm}$ & $77-101 \mathrm{~cm}$ & $76-99 \mathrm{~cm}$ \\
\hline 4 & $101-125 \mathrm{~cm}$ & $102-130 \mathrm{~cm}$ & $101-129 \mathrm{~cm}$ \\
\hline
\end{tabular}




\section{Pengujian Buzzer}

Buzzer aktif mengeluarkan suara berdasarkan pendeteksian jarak jangkauan objek pada sensor Ultrasonic dan suara yang dikeluarkan berbeda-beda. Ketika jarak penghalang $<50 \mathrm{~cm}$ bunyi berkedip sangat cepat, jika jarak penghalang $<76 \mathrm{~cm}$ bunyi berkedip lambat, jika jarak penghalang $<101 \mathrm{~cm}$ berkedip lebih lambat dan jika jarak penghalang $>102 \mathrm{~cm}$ bunyi berkedip sangat lambat, jika jarak penghalang $>130 \mathrm{~cm}$ maka tidak berbunyi. Pengujian buzzer dengan cara menghitung jarak objek sensor ultrasonic dengan jeda waktu yang berbeda-beda.

Tabel 4.2. Hasil Pengujian Suara Buzzer

\begin{tabular}{|c|c|c|c|}
\hline Uji & Jarak Objek & Jeda Waktu & Kondisi \\
\hline \hline 1 & $5-50 \mathrm{~cm}$ & 0,1 detik & Hidup \\
\hline 2 & $51-76 \mathrm{~cm}$ & 0,25 detik & Hidup \\
\hline 3 & $77-101 \mathrm{~cm}$ & 0,5 detik & Hidup \\
\hline 4 & $102-130 \mathrm{~cm}$ & 1 detik & Hidup \\
\hline
\end{tabular}

3. Pengujian Keseluruhan

Pengujian alat secara keseluruhan pada pengujian jarak jangkauan objek dan bunyi peringatan. alat ini aktif jika switch dalam keadaan on/hidup dan sensor akan mendeteksi objek didepan kemudian Buzzer akan hidup seperti pada keterangan tabel 3.

Tabel 4.3. Hasil Pengujian Keseluruhan

\begin{tabular}{|c|c|c|c|c|c|}
\hline Uji & $\begin{array}{c}\text { Jarak yang } \\
\text { ditentukan }\end{array}$ & Jarak Objek & $\begin{array}{c}\text { Jarak pada } \\
\text { Software }\end{array}$ & Jeda Waktu & Kondisi \\
\hline \hline 1 & $5-50 \mathrm{~cm}$ & $5-50 \mathrm{~cm}$ & $5-49 \mathrm{~cm}$ & 0,1 detik & Hidup \\
\hline 2 & $51-75 \mathrm{~cm}$ & $51-76 \mathrm{~cm}$ & $51-74 \mathrm{~cm}$ & 0,25 detik & Hidup \\
\hline 3 & $76-100 \mathrm{~cm}$ & $77-101 \mathrm{~cm}$ & $76-99 \mathrm{~cm}$ & 0,5 detik & Hidup \\
\hline 4 & $101-125 \mathrm{~cm}$ & $102-130 \mathrm{~cm}$ & $101-129 \mathrm{~cm}$ & 1 detik & Hidup \\
\hline
\end{tabular}

\section{Penerapan Elbow Crutch Portable berbasis sensor Ultrasonic}

1. Penggunaan pada orang Sakit Kaki/Cedera Kaki

Alat bantu elbow crutch portable ini dapat digunakan untuk orang sakit kaki/cedera kaki karena alat ini cukup ringan, lebih praktis, dan lebih mudah digunakan. Walaupun alat ini cukup ringan dan kuat karena terbuat dari bahan Aluminium alloy mampu menompang berat badan orang hingga $100 \mathrm{~kg}$. 


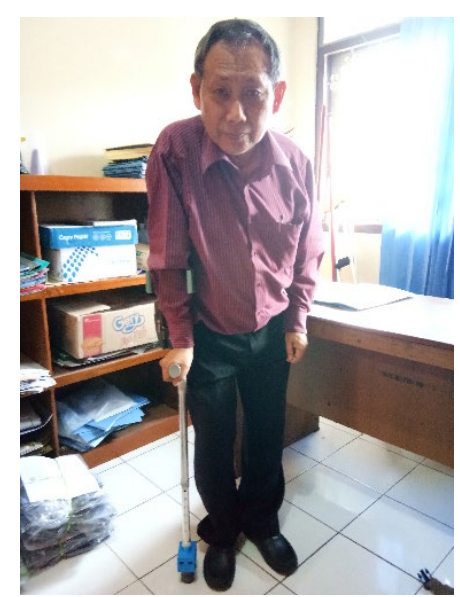

Gambar 13. Penggunaan pada orang Sakit Kaki/Cedera Kaki

2. Penggunaan pada orang penyandang Disabilitas

Alat bantu elbow crutch portable dapat juga digunakan untuk orang penyandang disabilitas karena cukup ramping dan dapat dilipat sehingga tidak mengganggu aktifitas bahkan alat bantu jalan kruk tipe elbow ini dapat digunakan untuk aktifitas olahraga. Berbeda dengan kruk tipe axilla yang cukup berat dan tidak lincah untuk aktifitas.

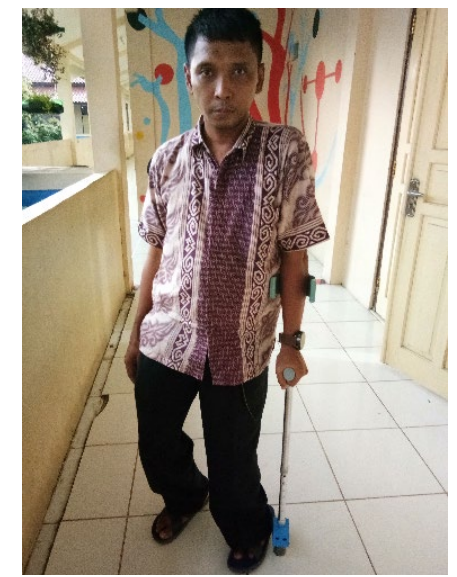

Gambar 14. Penggunaan pada orang penyandang Disabilitas

\section{Pendapat pengguna Elbow Crutch Portable}

Pendapat tentang penggunaan alat bantu ini bermacam-macam dilihat dari beberapa faktor dari kenyamanan, kemudahan dan keefektifan waktu lepas pasang sambungan lipat pada kruk ini dengan kategori responden yang berbeda. Berikut beberapa contoh pendapat orang tentang penggunaan alat elbow crutch portable ini. 
Tabel 4. Hasil Kuisioner Responden

\begin{tabular}{|c|c|c|c|c|c|}
\hline \multirow{2}{*}{ No } & \multirow{2}{*}{$\begin{array}{c}\text { Data } \\
\text { Responden }\end{array}$} & \multirow{2}{*}{ Pendapat Responden } & \multicolumn{2}{|c|}{ Efektifan Waktu } & \multirow{2}{*}{$\begin{array}{c}\text { Kategori } \\
\text { Responden }\end{array}$} \\
\hline & & & Lepas & Pasang & \\
\hline 1 & $\begin{array}{l}\text { Agung } \\
\text { Hastaman } \\
\text { Silarto } \\
\text { Guru } \\
33 \text { Tahun }\end{array}$ & $\begin{array}{l}\text { - Ringan dan kokoh } \\
\text { - Cukup ramping dan mudah } \\
\text { - Mudah dipakai tidak berat } \\
\text { sensornya juga membantu dalam } \\
\text { berjalan }\end{array}$ & 13 detik & 20 detik & $\begin{array}{c}\text { Penyandang } \\
\text { Disabilitas }\end{array}$ \\
\hline 2 & $\begin{array}{l}\text { Tri Agus } \\
\text { Pedagang } \\
45 \text { Tahun }\end{array}$ & $\begin{array}{l}\text { - Ringan hampir sama seperti kruk } \\
\text { ketiak } \\
\text { - Simpel mudah disimpan dan } \\
\text { mengkilap } \\
\text { - Cukup mudah digunakan tapi } \\
\text { terbiasanya pakai kruk ketiak yang } \\
\text { badan bisa bertumpu biar tidak } \\
\text { pegal tangannya, sensor agak } \\
\text { kurang nyaman sama suaranya } \\
\text { mungkin dibuat getar saja }\end{array}$ & 14 detik & 18 detik & $\begin{array}{c}\text { Penyandang } \\
\text { Disabilitas }\end{array}$ \\
\hline 3 & $\begin{array}{l}\text { Yanuar } \\
\text { Ridho } \\
\text { Hartoyo } \\
\text { Pelajar } \\
15 \text { Tahun }\end{array}$ & $\begin{array}{l}\text { - Kuat } \\
\text { - Bagus bisa dilipat } \\
\text { - Kurang nyaman karena } 1 \text { kruk } \\
\text { belum terbiasa butuh } 2 \text { kruk karena } \\
\text { kakinya masih sakit }\end{array}$ & 10 detik & 15 detik & Cedera Kaki \\
\hline
\end{tabular}

\section{Analisis flexibilitas kekuatan Elbow Crutch Portable}

Analisis pengujian dengan simulasi software solidworks, Pengujian pada rangka kruk dengan beban pada bagian genggaman tangan beban maksimal sebesar 1000 N. Dimana beban berdasarkan berat badan manusia sebanding dengan gravitasi 9,8 m/s $\mathrm{s}^{2}$. Arah gaya penekan $100 \%$ menekan ke arah bumi.

\section{Von Mises Stress}

Pada pengujian yang di lakukan dengan memberi beban pada bagian genggaman tangan dan didapat hasil bahwa area yang tingkat stress paling rendah warna biru yaitu $0.000 \times 10^{0} \mathrm{~N} / \mathrm{m}^{2}$, dan tingkat stress paling tinggi warna merah yaitu $8.567 \times 10^{7} \mathrm{~N} / \mathrm{m}^{2}$ dan diketahui yield strength pada alat ini yaitu sebesar $2.068 \times 10^{8} \mathrm{~N} / \mathrm{m}^{2}$. 


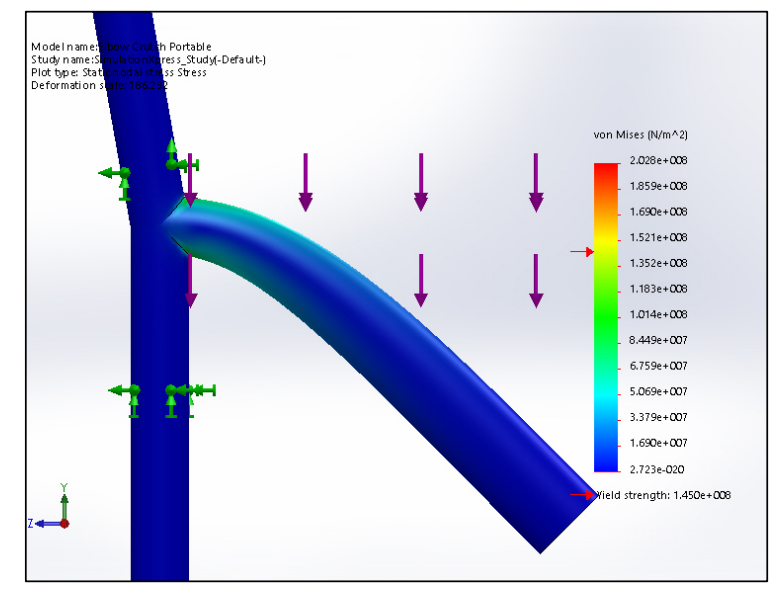

Gambar 15. Von Mises Stress

\section{Displacement}

Displacement atau pergerakan yang terjadi akibat beban. Seperti terlihat pada gambar yang warna biru merupakan nilai displacement minimum sedangkan nilai displacement maksimum berwarna merah sebesar $9.083 \times 10^{-2} \mathrm{~mm}$. Dengan posisi displacement yang terjadi berada diujung kerangka genggaman tangan.

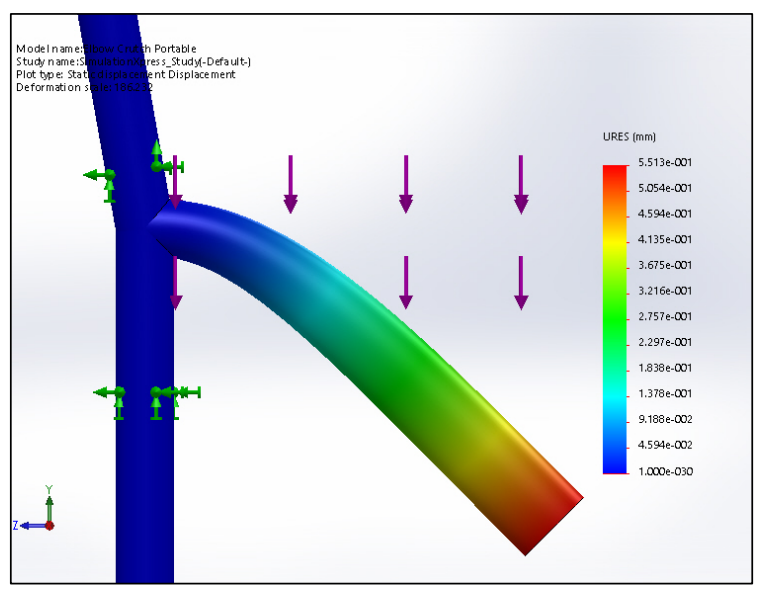

Gambar 16. Displacement

\section{KESIMPULAN}

Berdasarkan hasil pengujian dan analisis perancangan alat bantu jalan dapat disimpulkan sebagai berikut :

1. Perancangan dalam bentuk $2 \mathrm{D}$ dan $3 \mathrm{D}$ cukup penting sebelum pembuatan dan juga untuk mengetahui bentuk alat agar mendapatkan kepresisian sebuah alat. Alat ini terbagi menjadi 3 bagian untuk dapat lipat yaitu bagian atas, tengah, bawah dan dapat diatur 
ketinggian kruk pada bagian atas dan bawah dengan tinggi maksimal $112 \mathrm{~cm}$ dan minimal $94 \mathrm{~cm}$ untuk dewasa, tinggi maksimal $83 \mathrm{~cm}$ dan minimal $65 \mathrm{~cm}$ untuk anak-anak. Bagian bawah di lengkapi sistem kendali sensor untuk pendeteksi halangan didepan.

2. Pengujian sensor ultrasonic diketahui pendeteksian sensor $90 \%$ cukup presisi dengan perbandingan jarak yang ditentukan, jarak objek, jarak pada software arduino IDE dan jeda bunyi kedipan. Buzzer bekerja dengan baik dengan 4 kedipan yang berbeda. 0,1 detik pada jarak $<50 \mathrm{~cm}, 0,25$ detik, 0,5 detik, dan 1 detik pada jarak $>102 \mathrm{~cm}$. Berdasarkan pendeteksian jarak objek akan tetapi ada pendeteksian yang kurang presisi pada jarak $>130 \mathrm{~cm}$.

3. Hasil pengujian menggunakan simulasi software soliworks, diketahui stress maksimum $8.567 \times 10^{7} \mathrm{~N} / \mathrm{m}^{2}$ dan minimum $0.000 \times 10^{0} \mathrm{~N} / \mathrm{m}^{2}$ dengan diketahui yield strength pada genggaman tangan yaitu sebesar $2.068 \times 10^{8} \mathrm{~N} / \mathrm{m}^{2}$. Hasil displacement maksimum akibat beban pada genggaman tangan sebesar $9.083 \times 10^{-2} \mathrm{~mm}$.

\section{DAFTAR PUSTAKA}

Ahmad Taufiq Nugroho, 2011, "Perancangan Tongkat Sebagai Alat Bantu Jalan Bagi Lansia”, (Skripsi), Surakarta : Universitas Sebelas Maret.

Andreas, Wisnu Wendanto, 2016, "Tongkat Bantu Tunanetra Pendeteksi Halangan Menggunakan Sensor Ultrasonic Berbasis Microcontroller Arduino”, Jurnal Ilmiah Go Infotech, Vol. 22, No. $1: 24$ - 30, STMIK AUB, Surakarta.

Anung Budi Nugroho, 2011, "Perancangan Tongkat Tuna Netra Menggunakan Teknologi Sensor Ultrasonic Untuk Membantu Kewaspadaan Dan Mobilitas Tuna Netra”, (Skripsi), Surakarta : Universitas Sebelas Maret.

Ariska Oktarisa, 2016, "Rancang Bangun Tongkat Tunanetra Dengan Sistem Pendeteksi Objek Dan Kontur Daratan", (Tugas Akhir), Palembang : Politeknik Negeri Sriwijaya.

Egi Alva, 2017, "Software Sensor Ultrasonic Sebagai Pemandu Jalan Tuna Netra Berbasis Microcontroller", (Tugas Akhir), Padang : Politeknik Negeri Padang.

Fergiyawan, Andryana, Darusalam, 2018, "Alat Pemandu Jalan Untuk Penyandang Tunanetra Menggunakan Sensor Ultrasonic Berbasis Arduino”, Jurnal, Universitas Nasional, Jakarta.

Leonardus Antony Wibisono, 2016, "Pengendalian Rollbot Menggunakan Android Melalui Bluetooth Dan Android”, (Tugas Akhir), Yogyakarta : Universitas Sanata Dharma Yogyakarta.

Ridho Permata Putra, 2017, "Rancang Bangun Tongkat Tuna Netra Menggunakan Sensor Ultrasonic”, (Tugas Akhir), Padang : Politeknik Negeri Padang.

Rizki Azwar Rizko, 2014, "Perancangan Ulang Alat Bantu Jalan (Kruk) Berdasarkan Keinginan Pengguna Dengan Menggunakan Konsep Sistem Pengembangan Produk”, (Tugas Akhir), Riau : Universitas Islam Negeri Sultan Syarif Kasim Riau. 
Saidul, Hakim, Harpad, 2017, "Tongkat Tuna Netra Menggunakan Sensor Ultrasonic Berbasis Microcontroller ATmega 16”, Jurnal, Vol. 9, No. 2: 96 - 102, STMIK Widya Cipta Dharma, Samarinda.

Taufiq Fitriadi, 2008, "Perancangan Alat Bantu Jalan (Kruk) Yang Praktis Dan Ergonomis Dengan Menggunakan Software Catia”, (Tugas Akhir), Surakarta: Universitas Muhammadiyah Surakarta 